\title{
"Who Made These Rules? We're So Confused": An Introduction to the Special Issue on Critical Race Media Literacy
}

Andrea M. Hawkman

Utah State University

U. S. A.

Sarah B. Shear

University of Washington, Bothell

U.S. A.

ABSTRACT: In this introductory essay, editors of the special issue on critical race media literacy frame the current global contexts of race, racism, and media in which this issue is situated. Building from the work of authors included in this special issue, this essay calls readers to engage and disrupt racism in popular, educational, and other forms of media, both inside and beyond the classroom.

References

Guest Editor Contact

As we gather remotely to write this introduction, we are struck by the magnitude of this moment. The COVID-19 pandemic has brought into greater focus the harsh reality that the forces of white supremacy and capitalism value some lives more than others. Around the world, we see growing calls for racial justice, criminal justice reform, tribal sovereignty, environmental and public health safety, and economic revolution. These calls, their supporters, and their detractors find voice in and across a growing variety of media platforms. Widespread Internet access, 24-hour news cycles (e.g., BBC, CNN, Channel News Asia, Fox News), state-run media platforms (e.g., China Central Television, National Media Authority, Sana, TeleSUR), social media (e.g., Cyworld, Facebook, Instagram, KakaoStory, Twitter, Viadeo), online discussion forums (e.g., Reddit, 4chan, Sina Weibo, WeChat), streaming services (e.g., Hulu, Netflix, Amazon Prime), YouKu, YouTube, Spotify, and various print media (e.g., magazines, newspapers, books, graphic novels) all enable us and our students to connect with others, create communities, and gather information about the worlds in which we live. As such, naming and confronting systemic violence, whether racialized, gendered, sexualized, or ableist on television, film, and other forms of media is a skill set students around the world need. Through a critical engagement with media, students and teachers can understand how media shape our lives and how our lives can shape media. 
Critical race media literacy (CRML) calls educators to engage students in investigations of/with media (i.e., film, television, podcast, music, texts) in order to examine problematic representations of race/ism and people of color (Yosso, 2002). At its core, CRML assists students in understanding that all media messages (a) are generated by people; (b) utilize specific and intentional language; (c) are perceived in different ways; (d) are created from a specific perspective and are value-laden; and (e) are designed with the purpose of obtaining and maintaining power and/or profit (Kellner \& Share, 2005). As the lyrics, "who made these rules, we're so confused," from Lauryn Hill's 1998 song Everything is Everything suggest, media are shaped by a set of rules grounded in whiteness. These rules lead to misrepresentations, misunderstandings, and misappropriations that are experienced differently depending on the identities of individuals and institutions involved. We watch, read, and listen to the same media but experience them uniquely, and often struggle to communicate these differences.

In light of this, CRML offers a frame through which teachers and students can confront racist, colonial, classist, ableist, and heteronormative representations in media; interrogate the messages represented in problematic media messages; and navigate the complexities of representation in the classroom and society (Doerr-Stevens \& Buckley-Marudas, 2019; Hawkman \& Shear, 2017; Hawkman \& Van Horn, 2019; Kellner \& Share, 2005; King, 2017; Shear, 2018; Uzum, Yazan, Avineri, \& Akayoglu, 2019; Yazbak Abu Ahmad \& Hoter, 2019; Yosso, 2002). Teaching and learning critical race media literacy is paramount within and beyond classroom contexts in order for students to understand the nuanced ways media impacts how they make sense of the world around them.

Building from this understanding, this special issue presents 11 articles that engage critical race media literacy to challenge whiteness and racism in a variety of contexts and mediums. To begin, Tara Yosso reflects on her 2002 article "Critical Race Media Literacy: Challenging Deficit Discourse about Chicanas/os." In this essay, Yosso revisits the historical context in which her important work was conceived and offers thoughtful considerations for the continued application of CRML in our current and future realities. Next, Cheryl Matias deconstructs film and social media to demonstrate how whiteness is embedded in digital text and how CRML can be used pedagogically to help students read whiteness in these types of texts. In their work with 90 middle and high school students, Erin Lee Dyke, Jinan El Sabbagh, and Kevin Dyke share in the third article how student-created digital counterstory maps can be used to support educators' training towards culturally sustaining pedagogy. Next, highlighting data from two studies, Christine Rogers Stanton, Brad Hall, and Veronica Willeto DeCrane illuminate how studentled research and filmmaking in rural Indigenous communities opened spaces for place consciousness, civic engagement, intercultural dialogue and intergenerational understanding.

In the fifth article, Hyesun Cho and Peter Johnson share results from a study in which Korean female high school students raise critical awareness of racism and sexism in films with the help of their English-speaking teacher. Sarah Braden, 
in the sixth article, compares secondary students' metacommentary on the science nerd trope in media to their metacommentary on their own and their peers' classroom practices to shed light on CRML design elements for science education. In their critical content analysis of The Youngest Marcher, Noreen Naseem Rodriguez and Amanda Vickery demonstrate the need to engage young learners in civic media literacy through a critical race lens and offer ways for educators to nuance the limited narratives often found in children's literature.

In the eighth article, Tianna Dowie-Chin, Matthew Paul Stephens Cowley, and Mario Worlds provide a comparison of The Hate $U$ Give novel and adapted film to suggest classrooms engage deeper conversations about the functions of racism in the United States, including how the film weakened the novel's messages around racism and white supremacy. Tiffany Mitchell Patterson and Christine McWorther share in the ninth article how HBCU and PWI students' knowledge increased following their use of New York Times 1619 Project as Black historical media in class. Their study demonstrates how this content is underrepresented in both education and popular culture. In the tenth article, Ethan Chang develops legitimate digital participation to illustrate how young people used CRML to create humanizing cultural narratives and self-determined political identities. In the final article of the special issue, Ashley Cordes and Leilani Sabzalian articulate an understanding of anticolonial media literacy grounded in Indigenous ways of knowing that will help teachers detect and interrupt colonial logics.

We are profoundly moved by the work shared in this special issue and hope readers heed the call to disrupt the rules of whiteness in media through engaging CRML in their classrooms.

\section{References}

Doerr-Stevens, C., \& Buckley-Marudas, M. (2019). Hearing knowledge into action: Mobilizing sound for multicultural imaginaries. International Journal of Multicultural Education, 21(1), 105-124.

Hawkman, A.M., \& Shear, S.B. (2017). "They're gonna sing the songs anyway": Thinking and teaching with theory and Disney music for social studies. In W.B. Russell, III \& S. Waters (Eds.), Cinematic social studies: A resource for teaching and learning social studies with film (pp. 55- 78). Information Age Press.

Hawkman, A. M., \& Van Horn, S. E. (2019). What does it mean to be patriotic?: Policing patriotism in sports and social studies education. The Social Studies, 110(3), 105-121.

Hill. L. (1998). Everything is everything. The miseducation of Lauryn Hill. On Ruffhouse Records.

Kellner, D., \& Share, J. (2005). Toward critical media literacy: Core concepts, debates, organizations, and policy. Discourse: Studies in the Cultural Politics of Education, 26(3), 369-386. 
King, L. J. (2017). The media and black masculinity: Looking at the media through race[d] lenses. Critical Education, 8(2), 31-40.

Shear, S.B. (2018). Teaching and learning using Indigenous-made films. Social Studies Journal, 38(2), 20-29.

Shohat, E., \& Stam, R. (1994). Unthinking eurocentrism: Multiculturalism and the media. Routledge.

Uzum, B., Yazan, B., Avineri, N., \& Akayoglu, S. (2019). Preservice teachers' discursive constructions of cultural practices in a multicultural telecollaboration. International Journal of Multicultural Education, 21(1), 82-104.

Yazbak Abu Ahmad, M., \& Hoter, E. (2019). Online collaboration between Israeli Palestinian Arab and Jewish students: Fear and anxiety. International Journal of Multicultural Education, 21(1), 62- 81.

Yosso, T. J. (2002). Critical race media literacy: Challenging deficit discourse about Chicanas/os. Journal of Popular Film and Television, 30(1), 52-62. doi: https://doi.org/10.1080/01956050209605559

\section{Guest Editor Contact}

Andrea M. Hawkman, andrea.hawkman@usu.edu Utah State University, School of Teacher Education and Leadership 2805 Old Main Hill, Logan, Utah 84322

Sarah B. Shear, shearsb@uw.edu University of Washington, Bothell 18115 Campus Way NE, Bothell, WA 98011 